\title{
Urinary Excretion of Prednisolone after Intrarectal Therapy in Ulcerative Colitis
}

\author{
W. A. WOOD,* PH.D. ; G. WALTERS, $\dagger$ M.D., M.R.C.P. ; S. G. FLAVELL MATTS, $\ddagger$ M.B., CH.B., M.R.C.P.ED.
}

\author{
Brit. med. F., 1964, 2, 1045-1046
}

Treatment of ulcerative colitis with betamethasone phosphate enemas was found to cause suppression of the adrenal cortex, so that absorption of betamethasone from the rectum can be inferred; no suppression occurred in similar patients treated with prednisolone phosphate enemas (Matts, Wharton, Kelleher, and Walters, 1963). In order to determine whether any rectal absorption of prednisolone does occur, we have estimated the unconjugated prednisolone and metabolites in the urine of such patients.

\section{Materials and Method}

Studies were made on four patients with ulcerative colitis treated with prednisolone phosphate enemas, and on three normal subjects and two other patients with a collagen disease given oral prednisolone phosphate.

The patients with ulcerative colitis were studied during the first two days of treatment, which then consisted of one enema containing $20 \mathrm{mg}$. of prednisolone morning and night. Two 24-hour collections of urine were obtained, and in one patient a third collection was also obtained during the 24 hours immediately preceding the first dose.

The three normal subjects took a single oral dose containing $20 \mathrm{mg}$. of prednisolone dissolved in water, and urine was collected over the next 24 hours; in two of them a 24-hour collection was also obtained before prednisolone was taken.

The other two patients used as controls were being treated with $60 \mathrm{mg}$. of oral prednisolone daily, and a single 24-hour collection was obtained during treatment.

Prednisolone in urine was estimated by the method of Bailey, Murphy, and West $(1961,1963)$. Aliquots of urine containing about $20 \mu \mathrm{g}$. of prednisolone were extracted with 4 volumes of ether: ethyl acetate $(2: 1, v / v)$, and, after washing, the extracts are evaporated to small volume. Standard procedures for quantitative steroid chromatography were used (Bush, 1961). After a preliminary separation with benzene: methanol: water $(2: 1: 1, \mathrm{v} / \mathrm{v})$, a final resolution was made with toluene : methanol: water $(4: 3: 1, \mathrm{v} / \mathrm{v})$. Standards and unknowns were located with ultra-violet light of wavelength $253 \mathrm{~m} \mu$, and then eluted and estimated spectrophotometrically after reaction with isonicotinic acid hydrazide (Umberger, 1955). All results were corrected for incomplete recovery.

\section{Results}

The second chromatogram obtained by the above method showed, in addition to prednisolone and prednisone, two other areas which reacted with isonicotinic acid hydrazide. One of these (fraction 1) remained at the origin, while another compact area (fraction 4) was just behind the solvent front. The latter probably corresponded to the unidentified area found in similar urine extracts by Sandberg and Slaunwhite (1957) following

\footnotetext{
* Present address: The Department of Medicine, the Royal Infirmary, Manchester 13.

† Group Chemical Pathology Laboratory, New Cross Hospital, Wolverhampton.

$\ddagger$ The Royal Hospital, Wolverhampton. In receipt of a grant from the Birmingham Regional Hospital Board.
}

oral administration of prednisolone. It was found that extracts of urine collected before the administration of prednisolone also contained material which reacted with isonicotinic acid hydrazide, and, while the amount was negligible compared with the values obtained after large oral doses, it was significant in the cases receiving intrarectal treatment. The mean pre-treatment values have been subtracted from the results given in Tables I and II, where the urine values are expressed as a percentage of the dose.

\begin{tabular}{|c|c|c|c|c|c|c|}
\hline \multirow{2}{*}{ Subject } & \multirow{2}{*}{$\begin{array}{c}\text { Total } \\
\text { Daily Dose } \\
\text { of Pred- } \\
\text { nisolone } \\
\text { (mg.) }\end{array}$} & \multicolumn{5}{|c|}{ Amount Excreted, as a Percentage of Dose } \\
\hline & & $\begin{array}{c}\text { Pred- } \\
\text { nisolone }\end{array}$ & $\begin{array}{l}\text { Pred- } \\
\text { nisone }\end{array}$ & $\underset{1}{\text { Fraction }}$ & $\underset{4}{\text { Fraction }}$ & Total \\
\hline $\begin{array}{l}1 \\
2 \\
3 \\
4 \\
5\end{array}$ & $\begin{array}{l}20 \\
20 \\
20 \\
60 \\
60\end{array}$ & $\begin{array}{r}14.8 \\
8.5 \\
13.2 \\
13.7 \\
10.9\end{array}$ & $\begin{array}{l}4.9 \\
1.9 \\
1.0 \\
=\end{array}$ & $\begin{array}{l}2.5 \\
0.4 \\
0.6 \\
-\end{array}$ & $\begin{array}{l}1.1 \\
1.5 \\
0.8 \\
=\end{array}$ & $\begin{array}{c}23.2 \\
12.3 \\
15.6 \\
=\end{array}$ \\
\hline Mean & & $12 \cdot 2$ & $2 \cdot 6$ & $1 \cdot 1$ & $1 \cdot 1$ & $17 \cdot 0$ \\
\hline
\end{tabular}

TABLE II.-Urinary Excretion of Unconiugated Prednisolone and Metabolites after Rectal Prednisolone Phosphate in Patients with Ulcerative Colitis

\begin{tabular}{|c|c|c|c|c|c|c|}
\hline \multirow{2}{*}{ Patient } & \multirow{2}{*}{$\begin{array}{c}\text { Total } \\
\text { Daily Dose } \\
\text { of Predniso- } \\
\text { lone* (mg.) }\end{array}$} & \multicolumn{5}{|c|}{ Urinary Excretion (as a Percentage of Total Dose) } \\
\hline & & $\begin{array}{c}\text { Pred- } \\
\text { nisolone }\end{array}$ & $\begin{array}{l}\text { Pred- } \\
\text { nisone }\end{array}$ & $\underset{1}{\text { Fraction }}$ & $\begin{array}{c}\text { Fraction } \\
4\end{array}$ & Total \\
\hline $1\left\{\begin{array}{l}1 \text { st } 24 \text { hours } \\
2 \text { nd } 24 \text { hours }\end{array}\right.$ & $\begin{array}{l}40 \\
40\end{array}$ & $\begin{array}{l}4.0 \\
0.5\end{array}$ & $\begin{array}{l}1 \cdot 1 \\
0 \cdot 4\end{array}$ & $\begin{array}{l}2 \cdot 7 \\
0 \cdot 2\end{array}$ & $\begin{array}{l}0.6 \\
0.4\end{array}$ & $\begin{array}{l}8.4 \\
1.5\end{array}$ \\
\hline $2\left\{\begin{array}{l}1 \text { st } 24 \text { hours } \\
2 \text { nd } 24 \text { hours }\end{array}\right.$ & $\begin{array}{l}40 \\
40\end{array}$ & $\begin{array}{l}0.5 \\
1 \cdot 2\end{array}$ & $\begin{array}{l}0 \cdot 3 \\
0 \cdot 2\end{array}$ & $\begin{array}{r}0 \\
0 \cdot 2\end{array}$ & $\begin{array}{r}0 \\
0 \cdot 2\end{array}$ & $\begin{array}{l}0.8 \\
1.8\end{array}$ \\
\hline $3\left\{\begin{array}{l}1 \text { st } 24 \text { hours } \\
2 \text { nd } 24 \text { hours }\end{array}\right.$ & $\begin{array}{l}40 \\
40\end{array}$ & $\begin{array}{l}2 \cdot 8 \\
2 \cdot 6\end{array}$ & $\begin{array}{l}1.4 \\
0.9\end{array}$ & $\begin{array}{l}0.3 \\
0.5\end{array}$ & $\begin{array}{l}0.2 \\
0.6\end{array}$ & $\begin{array}{l}4 \cdot 7 \\
4 \cdot 6\end{array}$ \\
\hline $4\left\{\begin{array}{l}1 \text { st } 24 \text { hours } \\
2 \text { nd } 24 \text { hours }\end{array}\right.$ & $\begin{array}{l}40 \\
40\end{array}$ & $\begin{array}{l}0 \cdot 1 \\
2 \cdot 6\end{array}$ & 二 & 二 & 二 & - \\
\hline Mean & & $1 \cdot 8$ & $0 \cdot 7$ & 0.6 & $0 \cdot 3$ & 3.6 \\
\hline
\end{tabular}

- Given in two doses separated by 12 hours.

In the five control subjects the mean excretion of free prednisolone in 24 hours was $12.2 \%$ of the dose, with a range of 8.5 to $14.8 \%$. The total excretion of prednisolone plus unconjugated metabolites was determined in the three normal subjects, and this ranged from 12.3 to $23.2 \%$, with a mean of $17.0 \%$ of the dose. Lower values were found in the urine of patients given enemas (Table II). The 24-hour excretion of prednisolone averaged $1.8 \%$ of the dose (range 0.1 to $4.0 \%$ ) and the total of prednisolone plus free metabolites averaged $3.6 \%$ (range 0.8 to $8.4 \%$ ). In two cases there was a large difference between the two days.

\section{Discussion}

The absorption of prednisolone from the upper gastrointestinal tract has been studied with isotopically labelled prednisolone. More than $90 \%$ of the radioactivity was recovered from the urine by Sandberg and Slaunwhite (1957), and $98-99 \%$ by Vermeulen (1959), indicating that absorption was 
virtually complete. Unconjugated steroids were found to represent only a small part of the total excretion, but Bailey et al. (1961, 1963) observed that the amount of free prednisolone excreted was proportional to the dose given, and that excretion of free prednisolone was almost complete in eight hours (personal communication). With doses of up to $100 \mathrm{mg}$. approximately $10 \%$ of the dose was excreted as free prednisolone, and the results in our controls, which were obtained with basically the same method, are in agreement with this.

The results in the patients with ulcerative colitis show that prednisolone is absorbed to a variable extent from the rectum, but in relatively small amounts. The average excretion of free prednisolone in four patients was approximately one-sixth of that found after oral administration. The variation was much greater than in the subjects who took prednisolone orally, possibly owing to variations in the time of retention, although all the patients succeeded in retaining the enemas for at least two hours, which is thought to be the minimum time necessary therapeutically. In only one of the eight 24 -hour periods was the urine prednisolone more than $3 \%$ of the dose given, and the highest value of $4 \%$ is about one-third of the mean found after the oral dosage. Even this is less than the equivalent of $7 \mathrm{mg}$. of oral prednisolone for most of the therapeutic period, and is very unlikely to account for the efficacy of rectal treatment or to cause pituitary or adrenal cortical suppression.

We cannot say whether the suppression which follows treatment with betamethasone enemata is due to the more powerful suppressing effect of betamethasone or whether the rectal mucosa absorbs betamethasone to a greater extent.

\section{Summary}

An investigation was made to determine whether any rectal absorption of prednisolone-21-phosphate occurs after giving the therapeutic enemas. Direct estimations were made of the urinary excretion of prednisolone and metabolites after giving prednisolone either orally or rectally. in nine subjects. The results after correction for incomplete recovery were compared and an estimation of the amount of prednisolone absorbed following intrarectal administration of the therapeutic enemas of prednisolone was made. The results show that less than the equivalent of a daily oral dose of $7 \mathrm{mg}$. of prednisolone is absorbed from the rectum when a daily therapeutic enema regime of $40 \mathrm{mg}$. of prednisolone-21-phosphate is given to ulcerative colitis patients. This should not cause adrenal cortical or pituitary suppression, nor could it account for the therapeutic efficacy of the intrarectal method of treatment.

We are grateful to the Birmingham Regional Hospital Board for the grant which made this work possible, and to the physicians of the Royal Hospital for allowing us to investigate the patients under their care.

\section{REFERENCES}

Bailey, E., Murphy, D., and West, H. F. (1961). Lancet, 2, 347. Bus - (1963). Arch. Dis. Childh., 38, 71. Bush, I. E. (1961). The Chromatography of Steroids. Pergamon Press, Matts, S. G. F., Wharton, B. A., Kelleher, J., and Walters, G. (1963)
Brit. med.

Sandberg, A. A., and Slaunwhite, W. R. (1957). 7. chin. Endocr., 17, 1040 .

Umberger, E. J. (1955). Analyt. Chem., 27, 768.

Vermeulen, A. (1959). F. Endocr., 18, 278 .

\title{
Pain Following E.C.T. Modified by Muscle Relaxants
}

\author{
R. DEVINE,* м.B., CH.B.; K. J. NEWTON, $†$ м.в., CH.B., D.P.M. ; F. G. SPEAR, $\ddagger$ м.в., CH.в., D.P.M.
}

It has been suggested (Tewfik, 1963) that pain related to the administration of suxamethonium chloride is comparatively uncommon after E.C.T. Pain of this type occurring after operations in women where this drug has been used was first noted by Currie (1953). Later investigations report an incidence which varies from $20 \%$ (Hegarty, 1956) to around $70 \%$ (Churchill-Davidson, 1954 ; Morris and Dunn, 1957). It seems to be generally agreed that the symptom is commonest in out-patients and can be prevented to a certain extent by postoperative bed-rest (Burtles and Tunstall, 1961). These findings in patients who have had operations or been investigated under anaesthesia cast doubt on the clinical impression of a lowered incidence of muscular pain after suxamethonium chloride and E.C.T., as those receiving this treatment are of ten out-patients and nearly always ambulant. In view of this a prospective study of the incidence of pain in patients receiving suxamethonium chloride and E.C.T. has been carried out.

Patients undergoing electroplexy sometimes complain of headache after the treatment. All the clinical reports of pain after administration of suxamethonium chloride agree that the pain is muscular, occurring in the back, chest, and limbs. We can therefore examine the incidence of both headache and muscular pains and their relation to treatment.

* Temporary Lecturer in Psychiatry, University of Sheffield.

+ Senior House Officer, United Sheffield Hospitals.

Senior House Onchiatry, University of Sheffield.
All patients starting a course of E.C.T. between 17 September and 24 December 1963 were interviewed during the study. Four out-patients were omitted because the erratic nature of their attendance prevented adequate assessment. The results are derived from the findings on 47 patients $(22$ male and 25 female) aged 16-74 years (mean 41.62 years) who underwent a total of 259 anaesthetics and treatments.

Treatment was carried out twice a week and patients were interviewed on treatment days, before the arrival of the anaesthetist. They were told that the object of the investigations was to examine the possible side-effects of E.C.T. Attention was primarily directed to subjective loss of memory, and information about physical symptoms, including pain, was sought secondarily. Nevertheless, when pain was not reported spontaneously direct questions were asked, put in the form which " expects the answer no." The site, characteristics, and relation to treatment of the various pains reported were recorded. Muscular pain occurring after treatment in the neck, trunk, and limbs was regarded as related to the administration of suxamethonium chloride. Headache is considered separately. The presence of other pain related to the patient's illness was noted.

An Ectron machine was used to administer E.C.T. and the stimulus was given alternately by an "instant" or a "glisssando" method, as it was thought possible that the 